\title{
Biomechanics of Osteoporotic Fracture Fixation
}

\author{
Marianne Hollensteiner ${ }^{1,2} \cdot$ Sabrina Sandriesser ${ }^{1,2} \cdot$ Emily Bliven $^{1,2} \cdot$ Christian von Rüden $^{1,2,3} \cdot$ Peter Augat ${ }^{1,2}$
}

Published online: 21November 2019

(C) The Author(s) 2019

\begin{abstract}
Purpose of Review Fractures of osteoporotic bone in elderly individuals need special attention. This manuscript reviews the current strategies to provide sufficient fracture fixation stability with a particular focus on fractures that frequently occur in elderly individuals with osteoporosis and require full load-bearing capacity, i.e., pelvis, hip, ankle, and peri-implant fractures.

Recent Findings Elderly individuals benefit immensely from immediate mobilization after fracture and thus require stable fracture fixation that allows immediate post-operative weight-bearing. However, osteoporotic bone has decreased holding capacity for metallic implants and is thus associated with a considerable fracture fixation failure rate both short term and long term. Modern implant technologies with dedicated modifications provide sufficient mechanical stability to allow immediate weight-bearing for elderly individuals. Depending on fracture location and fracture severity, various options are available to reinforce or augment standard fracture fixation systems.

Summary Correct application of the basic principles of fracture fixation and the use of modern implant technologies enables mechanically stable fracture fixation that allows early weight-bearing and results in timely fracture healing even in patients with osteoporosis.
\end{abstract}

Keywords Bone $\cdot$ Fracture $\cdot$ Osteoporosis $\cdot$ Biomechanics $\cdot$ Osteosynthesis $\cdot$ Fragility fracture

\section{Introduction}

The healing of a fractured bone requires immobilization by conservative measures (i.e., cast or orthosis) or by surgical fixation with osteosynthesis implants (i.e., screws, plates, or nails). Fractures of osteoporotic bones are particularly challenging to treat for several reasons. First, the nature of osteoporotic bone itself, because of its decreased density and its increased brittleness, tends to fracture into more and smaller individual fragments creating more complex fractures than healthy bone [1]. This requires considerable surgical skills to achieve reduction and efficient implants for stable retention of the fracture. Second, osteoporotic fractures occur in elderly people who have

This article is part of the Topical Collection on Biomechanics

Peter Augat

biomechanik@bgu-murnau.de

1 Institute for Biomechanics, BG Unfallklinik Murnau, Prof.-Kuentscher-Str. 8, 82418 Murnau am Staffelsee, Germany

2 Institute for Biomechanics, Paracelsus Medical University, Salzburg, Austria

3 Department of Trauma Surgery, BG Klinikum Murnau, Murnau, Germany decreased capacity to manage functional limitations [2]. Ageassociated reductions in sense of balance, coordination, and proprioception combined with reduced vision result in uncoordinated limb loading and increased risk of falling [3]. Also, prescribed limitations in weight-bearing after fracture fixation often cannot be complied with, and lead to overloading of the fracture fixation constructs. This requires the fracture fixation to provide maximal stability in order to withstand immediate full weight-bearing. Third, osteoporosis is typically not the only condition elderly individuals have to deal with. Increasing age substantially increases the prevalence of comorbidities and the decline in organ function (heart, lung, kidneys, and liver). This makes elderly individuals much more vulnerable to post-traumatic complications and necessitates quick and minimally invasive surgery as well as rapid mobilization [4]. In terms of fracture fixation, this again requires sufficient mechanical stability to immediately mobilize the patient. Finally, osteoporotic bone has deteriorated mechanical properties reflected in porous cancellous and thin cortical bone resulting in reduced resistance to loading by rigid osteosynthesis implants. Consequently, implant loosening, implant cut out, and peri-implant fractures are frequent complications of osteoporotic fracture treatment [5]. Osteosynthesis implants thus need to either be designed to withstand loosening or be otherwise reinforced or augmented to prevent this type of 
failure. Overall, fracture fixation in elderly individuals with osteoporosis requires enduring stable fracture fixation with unrestricted load-bearing capacity. In this manuscript, the current strategies to provide sufficient fracture fixation stability will be reviewed with a particular focus on fractures that frequently occur in elderly individuals with osteoporosis [6] and which require full load-bearing capacity, i.e., pelvis, hip, ankle, and periimplant fractures.

\section{Hip Fractures}

Fractures of the proximal femur constitute a huge health and economic burden for societies all over the world [7] with incidence rates of up to 400 fractures per 100,000 individuals per year [8] and considerably higher fracture risk in women [9]. Thirty percent of hip fractures are caused by low-energy trauma and another $69 \%$ are spontaneous fractures [10]. Individuals suffering fragility fractures experience a drastic increase in mortality and morbidity. Excess mortality rates can be as high as $36 \%$ within the first year after hip fracture [11]. Their level of mobility and their quality of life is decreased and they often need care and supervision [12]. Only approximately one third of patients regain their previous mobility after a hip fracture [13].

Although cortical bone in the proximal femur is mainly responsible for the whole bone strength, cancellous bone still contributes to about $10 \%$ to the total strength in stance [14, 15 ] and $35 \%$ during a sideways fall [15]. Trauma mechanisms of femoral neck fractures may either be direct, e.g., fall onto the greater trochanter or a forced external rotation of the leg, or indirect, if muscle forces overwhelm the internal strength of the femur. As the femoral neck is intracapsular and thus not covered by periosteum, periosteal bone apposition is unable to compensate for cortical thinning caused by endosteal resorption. Thus, due to cortical thinning and trabecular bone loss, the femoral neck in particular loses strength and becomes susceptible to fracture. Similarly, as the lateral cortex of the trochanter becomes thinner during aging, it has a higher potential to buckle during a fall impacting the hip [16].

The AO/OTA fracture classification (Table 1) distinguishes extra-articular fractures in the trochanteric area (31-A), intraarticular fractures in the neck area (31-B), and fractures of the femoral head (31-C) [17].

The overall incidence rates of trochanteric and cervical fractures are similar, but the injuries possess etiologic and demographic differences. Women with trochanteric fractures are older, have more severe and generalized bone loss, and more frequently suffer from other osteoporotic fractures [18]. Fractures of the trochanter are most frequently multifragmentary pertrochanteric (A2), simple 2-fragment fractures (A1) in one third of the cases and rarely occur as reverse fractures (A3) [10]. Cervical fractures are frequently classified according to Pauwels considering the inclination of the fracture line or according to Garden considering their prognosis and potential complications [19-21]. The more recent classification from the $\mathrm{AO}$, which partly incorporates the Pauwels classification, additionally includes the fracture level and degree of displacement. Femoral neck fractures are thus classified as subcapital (31-B1), transcervical (31-B2), or basicervical (31-B3) fractures. Furthermore, fractures can be distinguished by being described as impacted, displaced, nondisplaced, simple, multifragmentary, or shear [17]. Femoral neck fractures are often simply described as displaced or nondisplaced because intra- and interobserver reliability is poor when using the various fracture classifications [20]. A displaced fracture is characterized by any detectable displacement of the fracture while non-displaced or impacted fractures show either an impacted valgus or simply no visible displacement [9].

\section{Treatment of Trochanteric Fractures}

While there is a general consensus on treatment of stable fractures (A1, A2), the best way to treat unstable fractures remains controversial [17]. Simple trochanteric fractures are treated by extra- or intramedullary devices [16, 22], mostly sliding hip screws and cephalo-medullary nails. While it appears that the use of cephalo-medullary nails is becoming more and more popular, there is no clear clinical evidence on the superiority of any surgical treatment method yet available [23]. For highly unstable subtrochanteric and reverse obliquity fractures, long cephalo-medullary devices have been shown to be the most successful treatment option [12].

Due to the lack of clear clinical evidence regarding the optimal surgical treatment, implant choice is often based on biomechanical performance. Biomechanical studies consistently show that cephalo-medullary nails perform biomechanically better than sliding hip screws, as they combine the advantages of the two options through a controlled impaction of the fracture and a closer-tocentral weight-bearing axis in the femoral shaft [24]. Concerning very unstable fractures, novel nail designs with interlocking lag screws provide improved mechanical performance over nails with single lag screws [25]. For extremely unstable fracture situations, cerclage wiring or auxiliary plates have shown to improve biomechanical stability [26]. It appears that these biomechanical findings translate well into clinical practice [26, 27].

Newly emerging implants such as angle-stable locking plates allow biological flexible fracture fixation based on the principle of an internal fixator [28]. Although they show excellent biomechanical performance [29], their clinical results are rather discouraging with catastrophic rates of nonunion (19\%) and mechanical failure (38\%) [30]. This contradiction might be explained by the bone healing mechanism in trochanteric fractures which differs from the healing mechanism in diaphyseal fractures. Diaphyseal fractures benefit from motion at the fracture site which is promoted by locking plates while trochanteric fractures heal more like cancellous bone fractures which benefit from accurate reposition and 
Table 1 The AO classification of proximal femur fractures (A: trochanteric area, B: the neck area, C: head area)
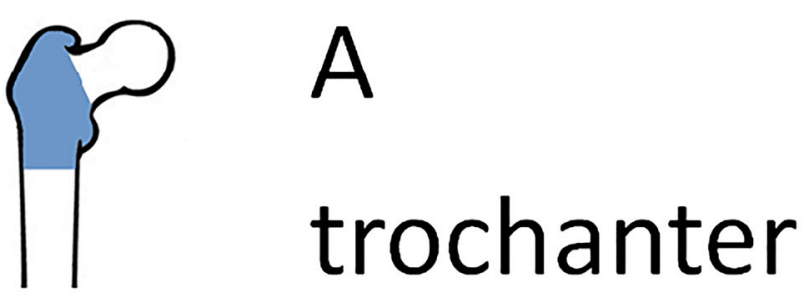

A1

pertrochanteric simple

A2

pertrochanteric multifragmentary

A3

intertrochanteric

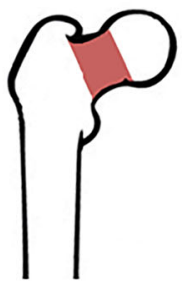

B

B1

subcapital, slight displacement

B2

neck

transcervical

B3

subcapital, displaced
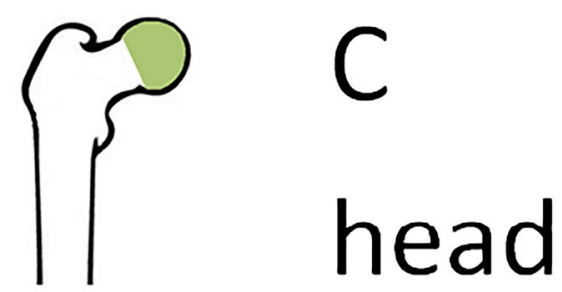

C1

split, Pipkin

C2

with depression

C3

with neck fracture

bone compression. Thus, despite biomechanical advantages, the locked plate may not induce the adequate healing response [31] and the plate might experience overloading during cyclic loading peak stresses, crack initiation, and propagation [32]. Thus, as long as the clinical evidence is still lacking, cephalo-medullary devices seem to be preferable over extramedullary implants when early weight-bearing is indicated.

\section{Treatment of Cervical Fractures}

Treatment of femoral neck fractures in elderly should enable early mobilization [9] and provide sufficient mechanical stability until the fracture has healed. It has been shown that the healing process heavily relies on the mechanical stability of the boneosteosynthesis construct, especially in comminuted fractures [33•]. Internal fixation by osteosynthesis is considered to be the standard form of treatment for non-displaced femoral neck fractures $[11,12]$. Non-comminuted, stable fractures are able to be securely fixated with use of only cannulated or hip screws [33•]. Commonly available techniques for unstable fractures include implementation of cannulated screws, hip screw systems (also with additional anti-rotation screws), proximal femur plates, and cephalo-medullary nails.

The main advantage of cannulated screws is that they are less invasive [9], apply compression to the fracture gap, and allow sliding of the head along the shaft axis, thus accelerating healing [33•]. The main problem when placing screws in osteoporotic femurs is that the central area of the femoral neck often lacks cancellous bone. Thus, biomechanical studies mainly focus on the necessary number, diameter, and position of screws, as such factors are of critical importance to resist displacement of the fracture gap and achieve bony union. Screw stability relies on anchorage at the lateral cortex on one side and the subchondral bone of the femoral head on the other [34]. Biomechanical studies report that screws with cortical support lead to higher stability than screws anchored in the cancellous bone alone [35]. Furthermore, fracture stability is increased when 3 instead of only 2 screws are placed [36]. Although additional screws increase construct stability, they may weaken the lateral cortex, necessary for proper screw anchorage [37]. From a biomechanical point of view, the recommended screw construct for femoral neck fractures is an inverted triangle configuration with three parallel screws. The parallel screw configuration enables sliding 
of the head fragment along the neck axis and thus further impaction of the neck [38]. The use of washers is additionally recommended, especially for osteoporotic bone, as they generate more compression in the fracture gap and prevent screw heads from penetrating the lateral cortex [39].

More vertically oriented fractures should be stabilized with sliding hip screws [40], which have been shown to be biomechanically superior to cannulated screws [41]. The potential risk of rotational malalignment is reduced by using additional antirotation screws [42]. A recently introduced novel hybrid between cannulated and sliding hip screws was reported to provide both rotational stability and controlled collapse of the femoral neck, combining the advantages of the individual options through smaller diameter sliding screws in a lateral locking plate. The novel implant has already shown reduced nonunion rates; however, more clinical evidence of its potential benefits is needed [43].

Another issue when treating femoral neck fractures is the shortening of the femoral neck. Historically this concern was accepted as a standard clinical outcome, but studies report severe impacts on patient's physical function [44]. In order to address this problem, new length-stable implants such as fully threaded cancellous screws, divergent cancellous screws, or proximal femoral locking plates have been introduced [9] with conflicting clinical results. A novel internal fixation technique combines two fully threaded divergent screws placed in the head and neck in combination with a sliding hip screw or dynamic helical blade, achieving a non-sliding construct. In $94 \%$ of patients treated with this method, the fracture healed with minimal shortening at the fracture site [45]. Catastrophic failure rates of $37 \%$ were reported in novel length-stable locking plates, leading authors to recommend against the usage of such an implant for the treatment of femoral neck fractures [46].

Despite all these developments, the rate of fixation failure with need for reoperation after femoral neck fracture osteosynthesis remains at around 40\% [47]. Age and low BMD have been identified as the most significant covariates for failure [48]. Thus, increased patient age and osteoporosis lead to a more frequent use of hip arthroplasty and has indeed shown to reduce reoperation rates and result in better functional outcome scores compared to osteosynthesis [11]. Hip arthroplasty as a technique provides a wide variety of options, including hemi or total hip replacement, fixed- or modular neck deigns, cemented or uncemented stems, and uni-, bi-, or even tripolar heads [9]. The decision to implant either total or hemiarthroplasty should be guided by several factors including the patient's age, activity level, and remaining life span.

\section{Ankle Fractures}

With increasing life expectancy, there is an increasing incidence of unstable ankle fractures, which affect mostly women and individuals with poor bone quality. The predominant trauma mechanism in $61 \%$ of fracture cases is a fall from standing height [49]. Age and osteoporosis are both considered to be risk factors for ankle fractures. When combined with comorbidities such as diabetes and obesity, the post-operative risk of nonunion is increased and makes fracture treatment challenging $[50-52 \cdot, 53,54]$. Ankle fractures are classified according to Danis-Weber type A, B, or C for the lateral malleolus [55, 56] and AO 43 for the distal tibia and fibula [57]. Non-operative treatment with a cast is only considered to be an option in cases of stable and non-displaced fractures, including isolated medial malleolar or isolated fibular fractures without syndesmotic rupture or instability [58-60]. Open reduction and internal fixation is required in all other more severe cases, in order to obtain a mechanically stable situation and restore the joint's functionality. For elderly patients who require early mobilization, the fracture fixation needs to be stable enough to allow immediate weight-bearing [61]. Depending on the type and severity of the fracture, stability can be achieved by internal fixation with plate osteosynthesis, intramedullary nailing, lag screws, or a combination thereof (Fig. 1).

Medial malleolar fractures can occur either as an isolated fracture or in combination with lateral malleolar and pilon fractures. If surgical intervention is required, this fracture can be reduced and stabilized by a lag screw, buttress plating, or wiring techniques $[62,63]$. Whereas malleolar fractures are mainly caused by rotational trauma, tibial plafond fractures, also known as pilon fractures, occur most often due to impaction of the articular surface $[64,65]$. The fragments should primarily be reduced by an external fixator until sufficient reduction of soft tissue swelling is achieved. In a secondary surgical intervention, the focus is on anatomical reduction of the articular surface, which should be performed in the posterior to anterior direction $[65,66]$. In a recent study, it was shown that anterolateral plating may not be sufficient in stabilizing the medial malleolar fragment [67]. To achieve sufficient stability, supplementation with an additional medial plate is recommended $[65,68]$. Regarding metaphyseal fragments, in rather simple fractures, absolute stability can be reached by the use of lag screws, whereas in comminuted fracture patterns, bridging constructs provide adequate stability [65]. Additional stability can be achieved by using the tibia for additional screw anchorage through trans-syndesmotic screw fixation even with an intact syndesmosis [60]. Depending on the fracture classification, such tibiofibular syndesmotic fixation is also recommended for Weber type $\mathrm{B}$ (fracture at the level of the syndesmosis) and type $\mathrm{C}$ (fracture proximal to the syndesmosis) fractures with partially torn or disrupted syndesmosis, in order to restore physiological tension and avoid talar displacement and post-traumatic osteoarthritis [69, 70].

Distal fibula fractures are commonly stabilized by either interfragmentary screws and neutralization plates or by plating alone. The controversy of whether locking plates are required for the fixation of lateral malleolar fractures has been recently 
Fig. 1 77-year-old female with bilateral complex displaced ankle fractures $(\mathbf{a}, \mathbf{b})$ and an associated Lisfranc injury in the left foot (b). Due to vulnerable soft tissue conditions, the right ankle was fixed using open reduction and internal angle-stable plate osteosynthesis of the distal fibula, temporary ankle joint Kirschner wire fixation, and lag screw fixation of the medial malleolus (c). The complex fracture on the left required primary transarticular tibiotalocalcaneal nailing (d)
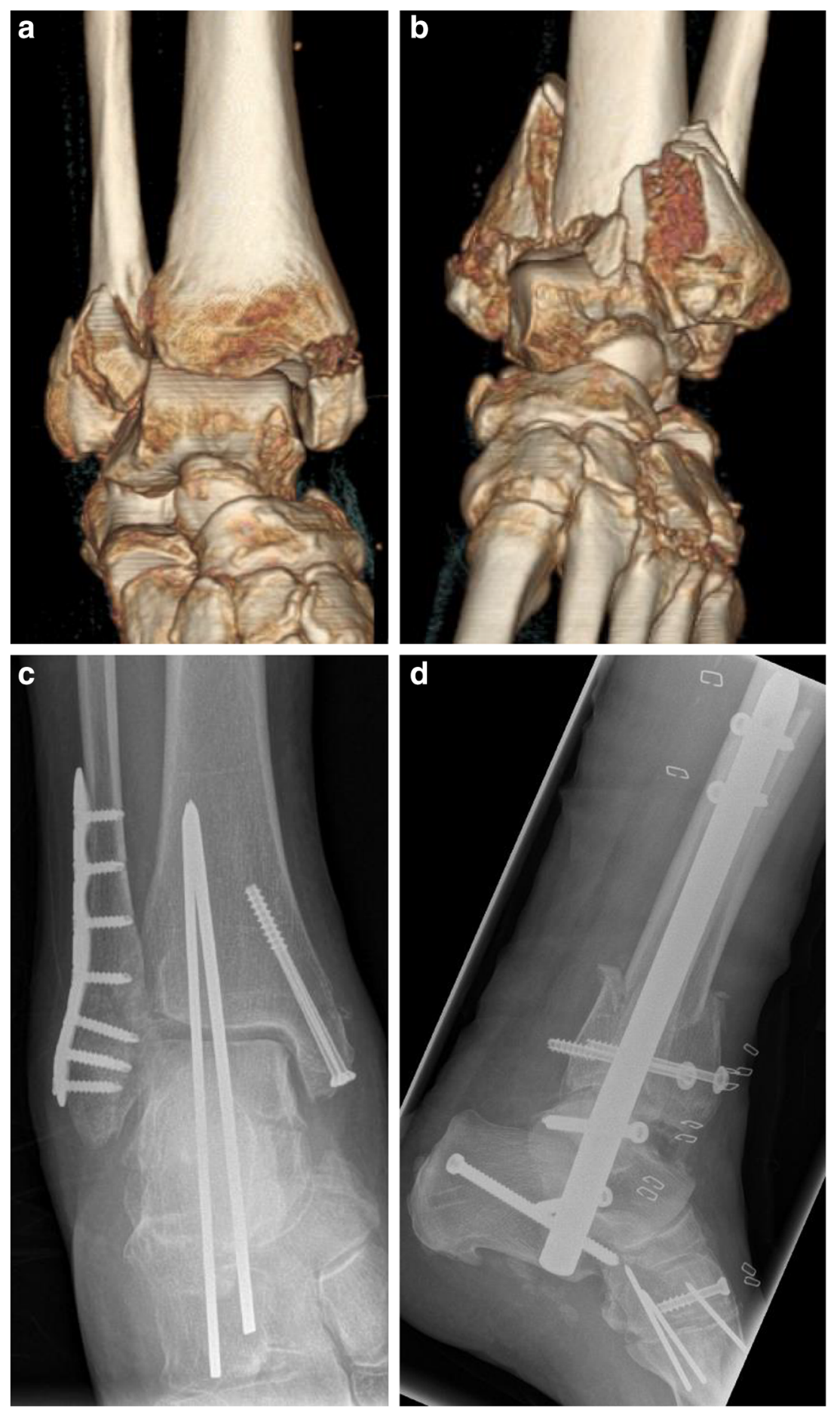

investigated in a meta-analysis of biomechanical studies [71]. It has been found that both locking as well as nonlocking plate constructs provide sufficient mechanical stability for the fixation of fibula fractures. Locking plates may show mechanical benefits compared to conventional plates for the fixation of fractures in highly osteoporotic bone. Intramedullary fixation of the distal fibula, instead of plating, may reduce soft tissue trauma due to incisions being smaller, as wound healing and infections play a crucial role in the clinical outcome of geriatric patients [72-74].

In very poor bone quality, internal fixation constructs can be augmented with cement like polymethylmethacrylate (PMMA) or resorbable calcium phosphate [75]. Both augmentation options increase construct stability and pull-out strength [60], as well as enable early weight-bearing and lower the risk of post-operative implant failure [76]. Tibiotalocalcaneal fusion is only considered as a last resort 
for pain reduction, and achieves this by eliminating joint motion. This complete stiffening of the ankle and hindfoot remains as an option for patients with minimal to no possibility of mobilization, or if other internal fixation techniques have been unable to provide sufficient stability [60, 77].

In general, the management of ankle fractures in elderly people with osteoporosis needs to be individually considered and the decision-making process can be based on functional demands and the presence of comorbidities with a primary aim of functional restoration allowing early post-operative mobilization [61].

\section{Pelvis Fractures}

The prevalence of pelvis fractures caused by low-energy trauma, such as falls from standing height, has drastically increased. Most pelvis fractures are linked to osteoporosis and occur in individuals that are 60 years and older [78]. The number of low-energy, fall-related fractures outnumbers high-energy fractures by 9 to 1 [6] and is expected to substantially increase [79]. Pelvis fractures constitute a significant clinical problem [6] [80] as they cause intense pain and immobility, impair the quality of life, and lead to loss of patients' independence [81]. In the elderly population, pelvis fractures are associated with a high morbidity and mortality with up to $27 \%$ of patients dying within 1 year of surgery $[82,83]$.

The pelvis can be thought of as a ring-shaped structure with anterior and posterior components. The biomechanically relevant and load-bearing structures are located in the posterior area of the pelvis. Fractures in this area lead to a biomechanical weakening of the load-bearing portion of the ring system and require surgical stabilization. Isolated fractures in the anterior region, where symphysis and adjacent pubic and ischial sections are located, do not lead to substantial mechanical weakening of the ring as these sections do not bear considerable loads but merely function as "bumpers" during walking. Osteoporosis-induced bone degeneration affects the posterior region of the pelvic ring especially, at the triangular surfaces on either side of the sacral base and the alae of the sacrum. Thus, typical fall-induced fracture patterns in the elderly include bilateral fractures in the sacral ala and iliac wings and compression of the lateral pelvis into the superior pubic ramus resulting in pelvic ring collapse and larger fracture displacements [84]. Recently, it has been reported that with increasing activity levels of elderly patients, there has been a shift towards more severe injury patterns [78] (Fig. 2).

The OA/OTA classification distinguishes between stable (A), rotationally unstable (B), and rotationally and vertically unstable (C) fractures. While "type A" fractures are rarely treated surgically, "C" fractures require surgical fixation due to loss of biomechanical stability. "Type B" fractures may require surgical treatment, in particular if immobilizing pain persists, fractures dislocate, or do not heal [85]. In order to address the specific situation of fractures in elderly, a dedicated classification system for fragility fractures of the pelvis (FFP) has been developed [81]. The FFP focuses on the degree of instability which poses the main basis for deciding whether to operate on the fracture or not.

The main objective of pelvic fracture treatment is pain relief and rapid mobilization with early full weight-bearing, as deemed appropriate regarding the patient's level of pain [83]. There is a need for specific surgical concepts for pelvic ring fractures in the elderly due to different fracture morphologies. Less invasive techniques including splinting and bridging in closed reduction are preferred over open reduction and internal fixation if sufficient mechanical stability can be achieved. Several biomechanical studies investigated construct stiffness and fracture displacement as measures of mechanical stability [81]. A widely accepted surgical technique is the use of percutaneous trans-sacroiliac screws inserted into the first and/or second sacral vertebral bodies [86]. Placement of two iliosacral screws achieves higher biomechanical stability than just one, and, similarly, longer screws achieve a higher stability than shorter ones [86, 87]. Clinically, screws often fail by loosening or unscrewing [85] due to reduced bone quality [81] which can be effectively addressed by using cannulated screws and bone cement to augment the fixation site [88, 89]. Bone cement is also an option for isolated and incomplete compression fractures [83] in which the cement is injected via a needle accessing the sacrum via the sacrum ala. This sacroplasty technique has been effective in decreasing pain
Fig. 2 78-year-old male following fall from an apple tree resulting in a comminuted acetabular fracture with displaced quadrilateral plate and acetabular dome also involving the anterior column (a). The fracture was fixated using a small fragment plate and cortical screws. An additional medial infrapectineal small fragment plate was placed to stabilize the displaced quadrilateral plate (b)
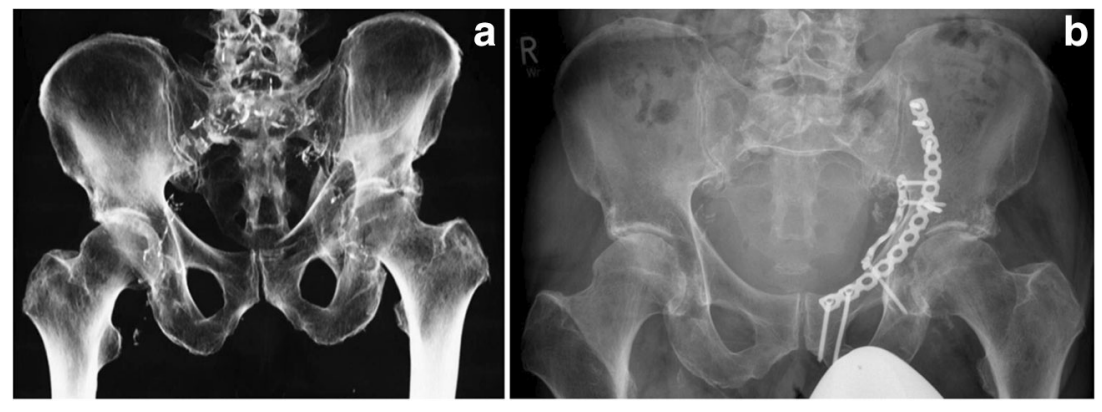


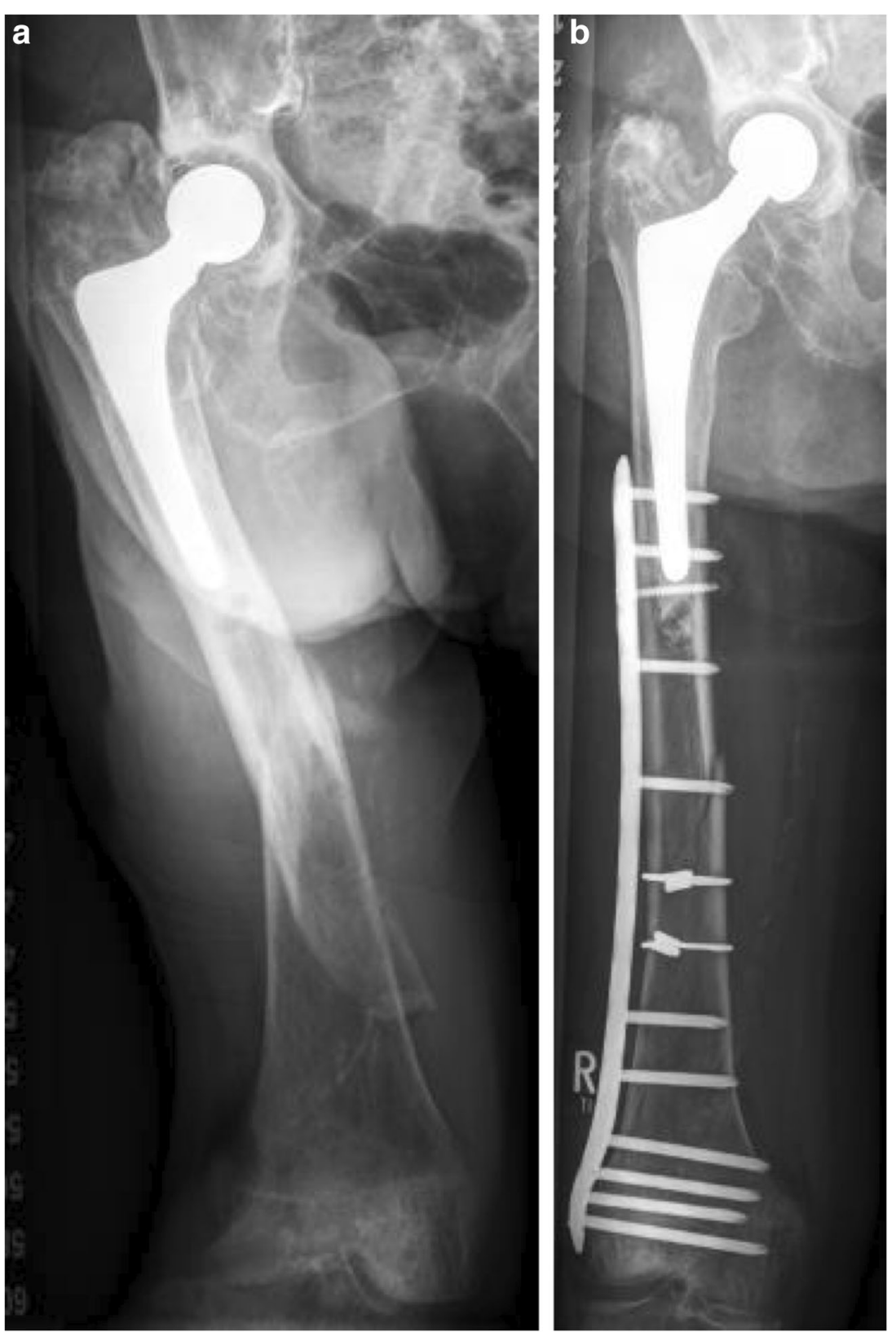

Fig. 3 Displaced periprosthetic femur fracture below the tip of the cemented arthroplasty stem (Vancouver type C) in a 90-year-old female treated by open reduction and internal fixation using two cerclages and a locking plate system

and improving quality of life also due to the analgesic effect of bone cement [90].

Fractures of the ilium lateral to the sacroiliac joint require bridging constructs like plate osteosynthesis [83] which have shown to be biomechanically superior when compared to single retrograde screw fixation [91]. Another possibility is transsacral bar osteosynthesis, where a threaded bar is inserted through the sacral corridor of the first sacral vertebra. The advantage of this bridging technique is that washers used to fix the bar prevent the screw heads from penetrating the bone. Therefore, construct stability does not depend on the trabecular bone affected by osteoporosis but rather on the cortical bone of the posterior ilium [92]. Unstable posterior ring fractures are treated with lumbopelvic fixation by means of sacroiliac screw osteosynthesis to achieve both horizontal and vertical stability [83]. Screws are therefore placed into the pedicle of the fifth lumbar vertebra and into the posterior ilium and then interconnected with a vertical rod. This so-called triangular osteosynthesis is more biomechanically stable than iliac screw osteosynthesis [93]. Posterior ring lesions are frequently combined with lesions of the anterior pelvic ring [81]. These injuries require surgical stabilization of both rings [94] as the fixation of only one side of the pelvis will not close the pelvic ring, subsequently leading to instability, higher stress in the placed osteosynthesis, and early implant failure. Additionally, the healing process will likely be decelerated. 
External fixation of pelvic ring fractures is often associated with complications like pin track infections, pin loosening $[81,95]$, and impairment of nursing, bathing, and early mobilization [95]. This minimally invasive fixation principle can also be employed subcutaneously by combining pedicle screws with curved rods placed over the pelvis [81]. Due to placement of rod closer to the bone surface, the subcutaneous placement has mechanical advantages compared to standard external fixator configurations [96].

\section{Periprosthetic Fractures}

The surgical treatment of osteoporotic fractures with metallic implants provides the opportunity for stable fracture fixation and the benefit of early weight-bearing for the patient. However, due to the vast differences in elasticity between the metallic implant and the osteoporotic bone, this method carries a substantial risk for fractures of the bone adjacent to the metal implants, so-called peri-implant or periprosthetic fractures. Although peri-implant fractures occur in essentially all long bone fracture fixations, they are by far the most frequently associated with fracture fixations of the femur.

Periprosthetic fractures at the femur (PFFs) are commonly described using the Vancouver classification. According to their region of fracture occurrence, PFFs are divided into trochanteric fractures (type A), stem level fractures (type B), and fractures distal to the stem (type C, Fig. 3) [97]. The classification of type $\mathrm{B}$ fractures depends on the status of the prosthesis: in type B1, the prosthesis is well-fixed, whereas in type $\mathrm{B} 2$, the prosthesis is loose, and in type B3, the prosthesis is loose with the addition of poor bone stock [98]. Type B fractures are reported to make up approximately $75 \%$ of all cases $[99,100]$.

The treatment of PFFs is demanding due to a combination of many factors: a fractured, often osteoporotic bone supporting a total hip prosthesis, which can also sometimes be cemented to anchor the prosthesis in poor bone stock. This scenario usually requires open reduction and internal fixation and eventually revision of the hip prosthesis. Displaced trochanter fractures (PFF type A) are challenging to treat as the trochanter fragment experiences shear and tension during weight-bearing. Thus, combinations of grip plates and cable or cerclage wires have been shown to be biomechanically advantageous [101] and are commonly applied clinically despite considerable complication rates [102]. Type B1 fractures should be treated by reduction and fixation with an invasive plate osteosynthesis, while B2 fractures require revision surgery with the implantation of a longer hip stem. B3 fractures require "salvage" procedures like a megaprosthesis or supplemental fixation with an allograft. Type $\mathrm{C}$ fractures, which occur below the hip stem, can be treated by fixation with long plates or by a combination of cerclages and struts [100].
A challenging factor in the treatment of type B PFFs is the presence of the prosthetic hip stem, which is quite often cemented. While sufficient fixation of the fracture should be achieved, the integrity of the cement mantle must be maintained and the stem should not be damaged by screws to avoid stem loosening or breakage [103•]. Solutions have been achieved by tangentially placing screws around the hip stem by the use of locking attachment plates, which are compatible with conventional locking compression plates [104], hook plates [105], or locking plates [106]. Modern locking plates allow polyaxial as well as bicortical screw placement around a hip stem [106] and sustain up to $40 \%$ higher failure loads than constructs of locking plates with additional superiorly mounted attachment plates [107]. Due to the voids of cancellous bone in the osteoporotic femur, the bicortical anchorage of screws in the cortex is essential to achieve biomechanical stability [106]. Bicortical tangential screw placement still carries the risk of the breach of cement mantle integrity and may lead to an early loosening of a cemented hip stem [108] due to cement mantle damage and crack formation. As the risk of a crack decreases with the distance of the screw in relation to the stem screws should be placed outside or at the periphery of the cement [109].

In comminuted fractures, one plate may not be stable enough for early weight-bearing, thus requiring stiffer and longer plates, additional cerclage wiring [110], or even double-plating constructs to prevent osteosynthesis failure [107]. These constructs require a large surgical approach and seriously deteriorate the healing capacity, thus serving as a permanent mechanical stabilizer. They may be a viable rescue option, especially for patients with unstable comminuted fractures, severe osteoporosis, over-weight, or other noncompliant patients with a need for immediate post-operative full weightbearing [111]. In unstable type $\mathrm{B} 3$ and type $\mathrm{C}$ fractures, a long stem revision in combination with a long plate often provides the only option for treatment $[112,113]$.

\section{Conclusion}

Fracture fixation in elderly individuals with osteoporosis requires stable fracture fixation that enables early mobilization of the patient and prevents fixation failure due to loosening, cut out, or peri-implant fracture. The consequent application of existing osteosynthesis techniques and choice of the most stable implant configuration can guarantee adequate fixation stability. Certain fracture situations may benefit from augmentation by cementing techniques or employing additional hardware such as auxiliary plates, cerclage wires, or doubleplating techniques. Novel implant techniques that have shown biomechanical benefits for osteoporotic fracture fixation still need to be evaluated with respect to their clinical performance. 
Acknowledgements Open access funding provided by Paracelsus Medical University.

\section{Compliance with Ethical Standards}

Conflict of Interest Marianne Hollensteiner, Sabrina Sandriesser, Emily Bliven, Christian von Rüden, and Peter Augat declare no conflict of interest.

Human and Animal Rights and Informed Consent This article does not contain any studies with human or animal subjects performed by any of the authors.

Open Access This article is distributed under the terms of the Creative Commons Attribution 4.0 International License (http:// creativecommons.org/licenses/by/4.0/), which permits unrestricted use, distribution, and reproduction in any medium, provided you give appropriate credit to the original author(s) and the source, provide a link to the Creative Commons license, and indicate if changes were made.

\section{References}

Papers of particular interest, published recently, have been highlighted as: • Of importance

1 Osterhoff G, Morgan EF, Shefelbine SJ, Karim L, McNamara LM, Augat $\mathrm{P}$. Bone mechanical properties and changes with osteoporosis. Injury. 2016;47(Suppl 2):S11-20.

2 Maki B, McIlroy W. Control of rapid limb movements for balance recovery: age-related changes and implications for fall prevention. Age Ageing. 2006;35:ii12-i8.

3 Rubenstein L. Falls in older people: epidemiology, risk factors and strategies for prevention. Age Ageing. 2006;35:ii37-41.

4 Rommens P. Paradigm shift in geriatric fracture treatment. Eur J Trauma and Emerg Surg. 2019;45(2):181-9.

5 von Rüden C, Augat P. Failure of fracture fixation in osteoporotic bone. Injury. 2016;47(Suppl 2):S3-S10.

6 Court-Brown C, Clement N, Duckwort A, Biant L, McQueen M. The changing epidemiology of fall-related fractures in adults. Injury. 2017:48:819-24.

7 Rapp K, Büchele G, Dreinhöfer K, Bücking B, Becker C, Benzinger P. Epidemiology of hip fractures: systematic literature review of German data and an overview of the international literature. Z Gerontol Geriatr. 2019;52(1):10-6.

8 Wallace I, Botiguè L, Lin M, Smaers JB, Henn B, Grine F. Worldwide variation in hip fracture incidence weakly aligns with genetic divergence between populations. Osteoporos Int. 2016;27: 2867-72.

9 Florschutz A, Langfordn J, Haidukewych G, Koval K. Femoral neck fractures: current management. J Orthop Trauma. 2015;29(3):121-9.

10 Barquet A, Giannoudis P, Gelink A. Femoral neck fractures after internal fixation of trochanteric fractures with implants in situ in adults: a systematic review. Injury. 2018;49:2121-31.

11 Rogmark C, Leonardsson O. Hip arthroplasty for the treatment of displaced fractures of the femoral neck in elderly patients. Bone Joint J. 2016;98(B):291-7.

12 Roberts K, Brox W, Jevsevar D, Sevarino K. Management of hip fractures in the elderly. J Am Acad Orthop Surg. 2015;23:131-7.

13 Hannson S, Rolfson O, Akesson K, Nemes S, Leonardsson O, Rogmark C. Complications and patient-reported outcome after hip fracture. A consecutive annual cohort study of 664 patiens. Injury. 2015;46:2206-11.

14 Holzer G, Skrebensky G, Holzer L, Pichl W. Hip fractures and the contribution of cortical vs. trabecular bone to femoral neck strength. J Bone Miner Res. 2009;24(3):468-74.

15 Nawathe S, Nguyen B, Barzanian N, Akhlaghpour H, Bouxsein $\mathrm{M}$, Keaveny T. Cortical and trabecular load sharing in the human femoral neck. J Biomech. 2015;48(15):816-22.

16 Reeve J. Role of the cortical bon in hip fracture. Bonekey Rep. 2017;6(87):1-10.

17 Meinberg EG, Agel J, Roberts CS, Karam MD, Kellam JF. Fracture and Dislocation Classification Compendium-2018. J Orthop Trauma. 2018;32(Suppl 1):S1-S170.

18 Augat P, Fan B, Lane N, Lang T, LeHir P, Lu Y, et al. Assessment of bone mineral at appendicular sites in females with fractures of the proximal femur. Bone. 1998;22(4):395-402.

19 van Embden D, Roukema G, Rhemrev S, Genelin F, Maylaerts S. The Pauwels classification for intracapsular hip fractures: is it reliable? Injury. 2011;42(11):1238-40.

20 Gaspar D, Crnkovic T, Durovic D, Podsenik D, Slisuric F. AO group, AO subgroup, Garden and Pauwels classification systems of femoral neck fractures: are they reliable and reproducible? Med Glas (Zenica). 2012;9(2):243-7.

21 Pauwels F. Der Schenkelhalsbruch: Ein mechanisches Problem. BJS. 1935;23(92):874.

22 Reindl R, Harvex E, Berry G, Rahme E. Intramedullary versus extramedullary fixation for unstable intertrochanteric fractures. J Bone Joint Surg. 2015;97(23):1905-12.

23 Queally J, Harris E, Handoll H, Parker M. Intramedullary nails for extracapsular hip fractures in adults. Cochrane Database Syst Rev. 2014;12(9):CD004961.

24 Valverde J, Alonso M, Porro J, Rueda D, Larrauri P, Soler J. Use of the gamma nail in the treatment of fractures of the proximal femur. Clin Orthop Relat Res. 1998;350:56-61.

25 Hoffmann S, Paetzold R, Stephan D, Püschel K, Buehren V, Augat P. Biomechanical evaluation of interlocking lag screw design in intramedullary nailing of unstable pertrochanteric fractures. J Orthop Trauma. 2013;27(9):483490.

26 Eberle S, Gabel J, Hungerer S, Hoffmann S, Patzold R, Augat P, et al. Auxiliary locking plate improves fracture stability and healing in intertrochanteric fractures fixated by intramedullary nail. Clin Biomech (Bristol, Avon). 2012;27(10):1006-10.

27 Wu D, Ren G, Peng C, Zheng X, Mao F, Zhang Y. InterTan nail versus Gamma3 nail for intramedullary nailing of unstable trochanteric fractures. Diagn Pathol. 2014;9:191-6.

28 Gueorguiev B, Lenz M. Why and how do locking plates fail? Injury. 2018;49(Suppl 1):S56-60.

29 Polat G, Akgül T, Ekinici M, Bayram S. A biomechanical comparison of three fixation techniques in osteoporotic reverse oblique intertrochanteric femur fracture with fragmented lateral cortex. Eur J Trauma Emerg Surg. 2019;45(3):499-505.

30 Streubel P, Moustoukas M, Obremsky W. Locked plating versus cephalomedullary nailing of unstable intertrochanteric femur fractures. Eur J Orthop Surg Traumatol. 2016;26(4):385-90.

31 Sommer C, Babst R, Muller M, Hanson B. Locking compression plate loosening and plate breakage: a report of four cases. J Orthop Trauma. 2004;18(8):571-7.

32 Stoffel K, Dieter U, Stachowiak G, Gachter A, Kuster MS Biomechanical testing of the LCP - how can stability in locked internal fixators be controlled? Injury. 2003;34(Suppl 2):B11-9.

33. Augat P, Bliven E, Hackl S. Biomechanics of femoral neck fractures and implications for fixation. J Orthop Trauma. 2019;33: S27-32 This article summarizes the available techniques for fracture fixation of the femoral neck and reviews them for their performance in terms of biomechanical stability. The 
authors emphasize the importance of load-bearing implants for unstable femoral neck fractures.

34. Ye Y, Hao J, Mauffrey C, Hammerberg E, Stahel P, Hak D. Optimizing stability in femoral neck fracture fixation. Orthopedics. 2015;38(10):625-30.

35. Lindequist S, Wredmark T, Eriksson SA, Samnegard E. Screw positions in femoral neck fractures: comparison of two different screw positions in cadavers. Acta Orthop Scand. 1993;64(1):6770.

36. Kauffmann J, Simon J, Kummer F, Pearlman C, Zuckermann J, Koval K. Internal fixation of femoral neck fractures with posterior comminution: a biomechanical study. J Orthop Trauma. 1999;13(3):155-9.

37. Maurer S, Wright K, Kummer F, Zuckermann J, Koval K. Two or three screws for fixation of femoral neck fractures. Am J Orthop (Belle Mead NJ). 2003;32(9):438-42.

38. Yang J, Lin L, Chao K, Chuang S, Yeh T, Lian Y. Risk factors for nonunion in patients with intracapsular femoral neck fractures treated with three cannulated screws placed in either a triangle or an inverted triangle configuration. J Bone Joint Surg Am. 2013;95(1):61-9.

39. Zlowodzki M, Wijdicks C, Armitage B, Cole P. Value of washers in internal fixation of femoral neck fractures with cancellous screws: a biomechanical evaluation. J Orthop Trauma. 2015;29(2):e69-72.

40. Liporace F, Gaines R, Collinge C, Haidukewych G. Results of internal fixation of Pauwels type-3 vertical femoral neck fractures. J Bone Joint Surg Am. 2008;90(8):1654-9.

41. Deneka D, Simonian P, Stankewich C, Eckert D, Chapman J, Tencer A. Biomechanical comaprison of internal fixation techniques for the treatment of unstable basicervical femoral neck fractures. J Orthop Trauma. 1997;11(5):337-43.

42. Bray T. Femoral neck fracture fixation. Clinical decision making. Clin Orthop Relat Res. 1997;339:20-31.

43. Thein R, Herman A, Kedem P, Chechik A, Shazar N. Osteosynthesis of unstable intracapsular femoral neck fracture by dynamic locking plate or screw fixation: early results. J Orthop Trauma. 2014;28(2):70-6.

44. Zielinski S, Keijsers N, Praet S, Heetveld M, Bhandari M, Wilssens J, et al. Femoral neck shortening after internal fixation of a femoral neck fracture. Orthopedics. 2013;36(7):e849-e58.

45. Boraiah S, Paul O, Hammoud S, Gardner M, Helfet D, Lorich D. Predictable healing of femoral nech fractures treated with intraoperative compression and length-stable implants. J Trauma. 2010;69(1):142-7.

46. Berkens M, Little M, Lazaro L, Cymerman R, Helfet D, Lorich D. Catastrophic failure after open reduction internal fixation of femoral neck fractures with a novel locking plate implant. J Orthop Trauma. 2012;26(10):e170-e6.

47. Broderick JM, Bruce-Brand R, Stanley E, Mulhall KJ. Osteoporotic hip fractures: the burden of fixation failure. Sci World J. 2013;2013:515197.

48. Hedstrom M. Are patients with a nonunion after a femoral neck fracture more osteoporotic than others? BMD measurement before the choice of treatment?: a pilot study of hip BMD and biochemical bone markers in patients with femoral neck fractures. Acta Orthop Scand. 2004;75(1):50-2.

49. Elsoe R, Ostgaard SE, Larsen P. Population-based epidemiology of 9767 ankle fractures. Foot Ankle Surg. 2018;24(1):34-9.

50. Warner SJ, Garner MR, Fabricant PD, Lorich DG. Bone density correlates with clinical outcomes after ankle fracture fixation. Arch Orthop Trauma Surg. 2018;138(12):1653-7.

51. Lee DO, Kim JH, Yoo BC, Yoo JH. Is osteoporosis a risk factor for ankle fracture?: Comparison of bone mineral density between ankle fracture and control groups. Osteoporos Sarcopenia. 2017;3(4):192-4.
52. Lacombe J, Cairns BJ, Green J, Reeves GK, Beral V, MEG A, et al. The effects of age, adiposity, and physical activity on the risk of seven site-specific fractures in postmenopausal women. J Bone Miner Res. 2016;31(8):1559-68 These authors explored the role of body mass index, age, and physical activity in different fracture sites in postmenopausal women. They revealed that physical activity reduces the risk of femur fracture. Additionally, that BMI has an impact on femoral fracture risk. Specifically, that higher BMI correlates with reduced fracture risk in the femoral neck area but an increased fracture risk in the remaining femur.

53. Dodd AC, Lakomkin N, Attum B, Bulka C, Karhade AV, Douleh DG, et al. Predictors of adverse events for ankle fractures: an analysis of 6800 patients. J Foot Ankle Surg. 2016;55(4):762-6.

54. Varenne Y, Curado J, Asloum Y. Salle de Chou E, Colin F, Gouin F. Analysis of risk factors of the postoperative complications of surgical treatment of ankle fractures in the elderly: a series of 477 patients. Orthop Traumatol Surg Res. 2016;102(4 Suppl):S245-8.

55. Danis R. Les fractures malleolaires. In: Danis R, editor. Theorie et Pratique de l'Osteosynthese. Paris: Masson; 1949. p. 133-65.

56. Weber B. Die Verlezungen des oberen Sprunggelenkes. 2nd ed. Verlag HansHuber: Bern; 1972.

57. Fonseca LLD, Nunes IG, Nogueira RR, Martins GEV, Mesencio AC, Kobata SI. Reproducibility of the Lauge-Hansen, DanisWeber, and AO classifications for ankle fractures. Rev Bras Ortop. 2018;53(1):101-6.

58. van Leeuwen CAT, Hoffman RPC, Donken C, van der Plaat LW, Schepers T, Hoogendoorn JM. The diagnosis and treatment of isolated type B fibular fractures: results of a nationwide survey. Injury. 2019;50(2):579-89.

59. Pogliacomi F, Schiavi P, Calderazzi F, Ceccarelli F, Vaienti E. When is indicated fibular fixation in extra-articular fractures of the distal tibia? Acta Biomed. 2019;89(4):558-63.

60. Rammelt S. Management of ankle fractures in the elderly. EFORT Open Rev. 2016;1(5):239-46.

61. Hoogervorst P, Bergen CV, Van den Bekerom M. Management of osteoporotic and neuropathic ankle fractures in the elderly. Curr Geriatr Rep. 2017;6(1):9-14.

62. Carter TH, Duckworth AD, White TO. Medial malleolar fractures: current treatment concepts. Bone Joint J. 2019;101-B(5):512-21.

63. Ebraheim NA, Ludwig T, Weston JT, Carroll T, Liu J. Comparison of surgical techniques of 111 medial malleolar fractures classified by fracture geometry. Foot Ankle Int. 2014;35(5):471-7.

64. Marsh JL, Saltzman CL. Ankle fractures. In: Bucholz RW, Heckman JD, Court-Brown CM, editors. Rockwood and Green's Fractures in Adults, vol. 2. 6th ed. Philadelphia, PA: Lippincott Williams \& Wilkins; 2006. p. 2147-247.

65. Bear J, Rollick N, Helfet D. Evolution in management of tibial pilon fractures. Curr Rev Musculoskelet Med. 2018;11(4):53745.

66. Busel GA, Watson JT. Plating of pilon fractures based on the orientation of the fibular shaft component: a biomechanical study evaluating plate stiffness in a cadaveric fracture model. J Orthop. 2017;14(2):308-12.

67. Aneja A, Luo TD, Liu B, Domingo M, Danelson K, Halvorson JJ, et al. Anterolateral distal tibia locking plate osteosynthesis and their ability to capture OTAC3 pilon fragments. Injury. 2018;49(2):409-13.

68. Penny P, Swords M, Heisler J, Cien A, Sands A, Cole P. Ability of modern distal tibia plates to stabilize comminuted pilon fracture fragments: is dual plate fixation necessary? Injury. 2016;47(8): 1761-9.

69. De-Las-Heras Romero J, AML A, Sanchez FM, Garcia AP, PAG $\mathrm{P}$, Sarabia RV, et al. Management of syndesmotic injuries of the ankle. EFORT Open Rev. 2017;2(9):403-9. 
70. Schnetzke M, Vetter SY, Beisemann N, Swartman B, Grutzner PA, Franke J. Management of syndesmotic injuries: what is the evidence? World J Orthop. 2016;7(11):718-25.

71. Dingemans SA, Lodeizen OA, Goslings JC, Schepers T. Reinforced fixation of distal fibula fractures in elderly patients; a meta-analysis of biomechanical studies. Clin Biomech (Bristol, Avon). 2016;36:14-20.

72. Kadakia RJ, Ahearn BM, Schwartz AM, Tenenbaum S, Bariteau JT. Ankle fractures in the elderly: risks and management challenges. Orthop Res Rev. 2017;9:45-50.

73. Dabash S, Eisenstein ED, Potter E, Kusnezov N, Thabet AM, Abdelgawad AA. Unstable ankle fracture fixation using locked fibular intramedullary nail in high-risk patients. J Foot Ankle Surg. 2019;58(2):357-62.

74. Tas DB, Smeeing DPJ, Emmink BL, Govaert GAM, Hietbrink F, Leenen LPH, et al. Intramedullary fixation versus plate fixation of distal fibular fractures: a systematic review and meta-analysis of randomized controlled trials and observational studies. J Foot Ankle Surg. 2019;58(1):119-26.

75. Windolf M. Biomechanics of implant augmentation. Unfallchirurg. 2015;118(9):765-71.

76. Panchbhavi VK, Vallurupalli S, Morris R. Comparison of augmentation methods for internal fixation of osteoporotic ankle fractures. Foot Ankle Int. 2009;30(7):696-703.

77. Wallace SJ, Liskutin TE, Schiff AP, Pinzur MS. Ankle fusion following failed initial treatment of complex ankle fractures in neuropathic diabetics. Foot Ankle Surg. 2019; S1268-7731(19): 30017-7.

78. Rollmann F, Herath S, Kirchhoff F, Braun B, Holstein J, Pohlemann T, et al. Pelvic ring fractures in the elderly women now and then - a pelvic registry study. Arch Gerontol Geriatr. 2017;71:83-8.

79. Kannus P, Parkkari J, Niemi S, Sievönen H. Low-trauma pelvic fractures in elderly Finns in 1970-2013. Calcif Tissue Int. 2015;97(6):557-80.

80. Massey P, James J, Bonvillain J, Nelson B, SR M, A H. Prevalence of Low Bone Mineral Density in Younger versus older women with distal radius fractures. The American Journal of Orthopedics. 2015; 44(12):493-6.

81. Rommens P, Wagner D, Hofmann A. Minimal invasive surgical treatment of fragility fractures of the pelvis. Chirurgie. 2017;112(5):524-37.

82. Andrich S, Haastert B, Neuhaus E, Neidert K, Arend W, Ohmann $\mathrm{C}$, et al. Excess mortality after pelvic fractures among older people. J Bone Miner Res. 2017;32(9):1789-801.

83. Oberkirchner L, Ruchholtz S, Rommens P, Hofmann A, Bücking B, Krüger A. Osteoporotic pelvis fractures. Dtsch Ärztebl Int. 2018;115:70-80.

84. Wagner D, Kamer L, Sawaguchi T, Richards G, Noser H, Rommens P. Sacral bone mass distribution assessed by averaged three-dimensional CT models. J Bone Joint Surg. 2016;98:584 90 .

85. Culemann U, Osetern H, Pohlemann T. Aktuelle Behandlung der Beckenfraktur. Unfallchirurg. 2014;117:145-61.

86. Rommens P, Hofmann A. Comprehensive classification of fragility fractures of the pelvic ring: recommendations for surgical treatment. Injury. 2013;44:1733-44.

87. Zwienen C, van den Bosch E, Snijders C, Kleinrensink G, van Vugt A. Biomechanical comparison of sacroiliac screw techniques for unstable pelvic ring fractures. J Orthop Trauma. 2004;18(9): 589-95.

88. Grueneweller N, Raschke M, Zderic I, Widmer D, Waehnert D, Gueorguiev B, et al. Biomechanical comparison of augmented versus non-augmented sacroiliac screws in a novel hemi-pelvis test model. J Orthop Res. 2017;35(7):1485-93.
89. Oberkircher L, Masaeli A, Bliemel C, Debus F, Ruchholtz S, Krüger A. Primary stability of three different iliosacral screw fixation techniques in osteoporotic cadaver specimens - a biomechanical investigation. Spine J. 2016;16(2):226-32.

90. Nicholson P, Hilditch C, Brinjiki W, Tsang A, Smith R. Singleneedle lateral sacroplasty technique. Spine. 2018;40:382-5.

91. Acklin Y, Zderic I, Buschbaum J, VArga P, Inzana H, Grechenig S, et al. Biomechanical comparison of plate and screw fixation in anterior pelvic ring fractues with low bone mineral density. Injury. 2016;47:1456-60.

92. Mehling I, Hessmann M, Rommens P. Stabilization of fatigue fratcures of the dorsal pelvis with a transsacral bar. Operative technique and outcome. Injury. 2012;43(4):446-51.

93. Schildhauer T, Ledoux W, Chapman J, Henley M, Tencer A, Routt M. Triangular osteosynthesis and iliosacral screw fixation for unstable sacral fractures: a cadaveric and biomechanical evaluation under cyclic loads. J Orthop Trauma. 2003;17(1):22-31.

94. Godinsky R, Vrabee G, Guseila L, Filipkowski D, Elias JJ. Biomechanical comparison of locked versus non-locked symphyseal plating of unstable pelvic ring injuries. Eur J Trauma Emerg Surg. 2018;44:179-84.

95. MacCormick L, Chen F, Gilbertson J, Khan S, Schroder L, Bechtold J, et al. A biomechanical study comparing minimally invasive anterior pelvic ring fixation techniques to external fixation. Injury. 2019;50:251-5.

96. Mcdonald E, Theologis A, Horst P, Kandemir U, Pekmezci M. When do anterior external or internal fixators provide additional stability in an unstable (Tile C) pelvic fracture? A biomechanical study. Eur J Trauma Emerg Surg. 2015;41:665-71.

97. Duncan C, Masri B. Fractures of the femur after hip replacement. Instr Course Lect. 1995;44:293-304.

98. Gaski G, Scully S. Classifications in brief: Vancouver classification of postoperative periprosthetic femur fractures. Clin Orthop Relat Res. 2011;469:1507-10.

99. Lochab J, Carrothers A, Wong E, McLachlin S, Aldebayan W, Jenkinson R, et al. Do transcortical screws in a locking plate construct improve the stiffness in fixation of Vancouver B1 periprosthetic femur fractures? A biomechanical analysis of 2 different plating constructs. J Orthop Trauma. 2017;31:15-20.

100. Duncan C, Haddad F. The unified classification system (UCS): improving our understanding of periprosthetic fractures. Bone Joint J. 2014;96(B):713-6.

101. Sariyilmaz K, Korkmaz M, Özkunt O, Gemalmaz H, Sungur M, Baydogan M, et al. Comparison of fixation techniques in Vancouver type AG periprosthetic femoral fracture: a biomechanical study. Acta Orthop Traumatol Turc. 2016;50(3):373-8.

102. McCarthy J, Bono J, Turnher R, Kremchek T, Lee J. The outcome of trochanteric reattachment in revision total hip arthroplasy with a Cable Grip System: mean 6-year followup. J Arthroplasty. 1999;14:810-4.

103. Moazen M, Jones AC, Jin Z, Wilcox RK, Tsiridis E. Periprosthetic fracture fixation of the femur following total hip arthroplasty: a review of biomechanical testing. Clin Biomech. 2011;26:13-22 This study provides an overview of both the opportunities and limitations of biomechanical assessments of periprosthetic fracture treatments of the femur. Currently available computational and experimental methodologies have been explored and evaluated.

104. Griffiths J, Taheri A, Day R, Yates P. Better axial stiffness of a bicortical screw construct compared to a cable construct for comminuted Vancouver B1 proximal femoral fractures. J Arthroplasty. 2015;30(12):2333-7.

105. Lenz M, Stoffel K, Kielstein H, Mayo K, Hofmann G, Gueorguiev B. Plate fixation in periprosthetic femur fractures Vancouver type B1-trochanteric hook plate or subtrochanterical bicortical locking? Injury. 2016;47:2800-4. 
106. Gwinner C, Märdian S, Dröge T, Schulze M, Raschke M, Stange R. Bicortical screw fixation provides superior biomechanical stability but devastating failure modes in periprosthetic femur fracture care using locking plates. Int Orthop. 2015;39(9):1749-55.

107. Wähnrert D, Schröder R, Schulze M, Weszerhoff P, Raschke M, Stange R. Biomechanical comparison of two angular stable plate fixation constructs for periprosthetic femur fracture fixation. Int Orthop. 2014;38:47-53.

108. Giesinger K, Ebneter L, Day R, Stoffel K, Yates P, Kuster M. Can plate osteosynthesis of periprosthethic femoral fractures cause cement mantle failure around a stable hip stem? A biomechanical analysis. J Arthroplasty. 2014;29:1308-12.

109. Konstantinidis L, Schmidt B, Bernstein A, Hiirschmüller A, Schröter S, Südkamp N, et al. Plate fixation of periprosthetic femur fractures: what happens to the cement mantle? J Eng Med. 2017;231(2):138-42.
110. Lenz M, Lehmann W, Wahnert D. Periprosthetic fracture fixation in osteoporotic bone. Injury. 2016;47(Suppl 2):S44-50.

111. Wähnert D, Grüneweller N, Gehweiler D, Brunn B, Raschke M, Stange R. Double plating in Vancouver type B1 periprosthetic proximal femur fractures: a biomechanical study. J Orthop Res. 2017;35(2):234-9.

112. Moazen M, Leonidou A, Pagkalos J, Marghoub A, Fagan M, Tsiridis E. Application of far cortical locking technology in periprosthetic femoral fracture fixation: a biomechanical study. $\mathrm{J}$ Arthroplasty. 2016;31(8):1849-56.

113. Gordon K, Winkler M, Hofstädter T, Dorn U, Augat P. Managing Vancouver B1 fractures by cerclage system compared to locking plate fixation - a biomechanical study. Injury. 2016;47(S2):51-7.

Publisher's Note Springer Nature remains neutral with regard to jurisdictional claims in published maps and institutional affiliations. 